Rodrigo Gabrioti

Universidade Metodista de São Paulo

ORCID iD https://orcid. org/0000-0001-67453600

\section{Caminhos para a Comunicação ser a Ciência do século 21}

\author{
Ways for the \\ Communicacation to be \\ the 21st Century's Science
}

\author{
Caminos para la \\ Comunicación ser la \\ Ciencia del siglo 21
}


Submissão: 11-1-2021

Decisão editorial: 25-6-2021

226 C\&S - São Bemardo do Campo, v. 43, n. 2, p. 225-233, maio-ago. 2021 
Resenha: BARBOSA, Marialva. Comunicação e método: cenários e práticas de pesquisa. Rio de Janeiro: Mauad X, 2020.

Para defender a Comunicação como saber síntese do século XXI, Marialva Barbosa faz de seu mais novo livro uma extensão da sua própria experiência, em décadas de sala de aula, como professora de Metodologia de Pesquisa. Nestes tempos em que a tecnologia prevalece e o exercício de um olhar endógeno indica hipoteticamente ser algo salutar ao desenvolvimento teórico-metodológico e conceitual da nossa área, a discussão da autora não se restringe apenas a uma grade curricular intramuros dos pósgraduandos em Comunicação e Cultura da UFRJ, a Universidade Federal do Rio de Janeiro, sejam aqueles que anos atrás ou pouco antes da pandemia do coronavírus frequentaram presencialmente suas aulas ou aqueles que, na pandemia, obrigatoriamente distanciados pelo bom senso do isolamento social, chegam a elas conectados por meio de plataformas virtuais. Assim, a obra resenhada extrapola a comunidade em questão e os leitores têm, a partir dessa publicação, um contato com os cenários de pesquisa, denominação definida pela autora. 
Inquietação comum a muitos dos que se projetam pela carreira acadêmica, o processo metodológico é apresentado, desde o primeiro contato com o livro, como construção e não como racionalidade exata. A segurança desta afirmação vem do trabalho da autora em reacender discussões e revisitar conceitos como dinâmica metódica dessa generalização do senso comum de que Metodologia é algo a ser aplicado em um objeto de estudo.

Em 161 páginas, o leitor de Comunicação e método: cenários e práticas de pesquisa vai se deparar com o conteúdo dividido em duas partes. Na primeira, menções ao conhecimento científico, campo teórico da Comunicação e suas trajetórias reflexivas que envolvem um panorama das perspectivas práticas no decorrer da formação da Área, no Brasil, até a amostra documental de 109 teses produzidas nos Programas de Pós-Graduação brasileiros em Comunicação cujas notas da Avaliação Trienal da Capes equivaleram a cinco ou mais, em 2017.

Ao tratar do conhecimento científico, Marialva faz um diagnóstico sobre a segunda década deste século XXI observando as condições culturais e comunicacionais que o presente nos oferece bem como a ressalva de que conhecimento, história e memória estão na mira de ataques. A partir dessa perspectiva e de um resgate de autores que tratam da Epistemologia, ela estabelece uma materialidade histórico-social que emana objetos a se conhecer, o que a coloca na esteira do pensamento de Karl Popper sobre o estudo do conhecimento cientifico para uma constituição epistemológica que inclui problemas, conjunturas, discussões, argumentos críticos e a evidência no contexto de pesquisa. Finaliza este estado da arte sobre o 
conhecimento cientifico mostrando (2020, p. 23) que "o principal problema da epistemologia é decidir se as formas do conhecimento pertencem ao sujeito, ao objeto ou a algum tipo de relação entre ambos".

Implicitamente pregando uma ruptura paradigmática, a autora compreende o conhecimento hoje em dia como uma nova história e propõe para isso que se religuem as Ciências Humanas; reflita-se sobre uma nova humanidade; respirem-se saberes e que se construam muros de contenção na compreensão/ explicação do humano. A sugestão de Barbosa se dá após um resgate entre materialidades constituídas e discutíveis para tempos incertos de negação e desconhecimento sobre quem é o sujeito de hoje, independentemente dos objetos.

Sobre o campo teórico da Comunicação, Marialva Barbosa aponta que não é possível falar em Metodologia sem conhecer as teorias de uma Área. Por isso, apresenta um pouco desse arcabouço, à luz de autores como Maria Immacolata Vassalo de Lopes, Luiz Carlos Martino, José Luís Braga, entre outros. Apesar de assumir que não seja esta sua principal temática de estudo, Marialva é ao mesmo tempo propositiva e crítica em relação às teorias, sobretudo, nas incertezas e inquietudes a respeito do conceito de Comunicação. Para isso, recupera uma das perspectivas de Muniz Sodré sobre a ciência do comum: a dimensão critico-cognitivo ou metacrítica da Comunicação', uma proposta de metapesquisa que me parece ser uma evidência epistemológica à Comunicação não apenas sistemática, mas crítica e com-

Ver mais sobre estes conceitos em: SODRÉ, Muniz. A ciência do comum: notas para o método comunicacional. Petrópolis, RJ: Vozes, 2014. 
parativa também para que, a partir dos resultados, se construam perspectivas e tendências.

A primeira parte do livro termina com a afirmação categórica da autora de que a Comunicação é a Ciência do século XXI. Para isso, resgata a trajetória do campo, no Brasil, pelos panoramas teóricos, a partir dos estudos em Comunicação, observados por décadas que culminam em institucionalização e registro das habilidades das subáreas do escopo da Comunicação. Esse resgate é fundamental para ela indagar quais são os estudos de Comunicação que dominam a segunda metade do século XXI para que seja feita uma análise das tendências construídas a partir da observação de uma amostra de teses pela qual se interessa em construir um campo de saber, sob novas bases, demonstrando novamente sua intenção em romper paradigmas. Entendendo que a Comunicação procura sua superação disciplinar dos saberes como modo de compreensão e interpretação do mundo, a autora propõe um novo marco (2020, p. 60): "[...] iniciamos as últimas décadas do século XX à procura do nexo comunicacional e chegamos ao século XXI com a percepção de que as pesquisas instituem a comunicação como definidora da ação humana no mundo".

\section{A Segunda parte}

A partir daqui, Marialva Barbosa dialoga com as teses cujas condutas metodológicas são analisadas e comentadas. Segundo ela, toda pesquisa tem origem em um tema ao qual se estabelece uma problematização, por sua vez, resultante de um levantamento bibliográfico que se articula objetivamente. Essa construção demanda um lugar teórico que estabelece 
uma coerência de pensamentos mesmo que, entre eles, haja divergências. Para que todo esse procedimento se cumpra, a autora acredita que o ponto de partida seja empírico. Com estas impressões, ela reforça as quatro etapas consolidadas de uma pesquisa científica: (1) planejamento; (2) coleta de dados; (3) análise e interpretação dos dados; (4) redação final. Em particular, a redação é mais um desafio suscitado, já que Marialva Barbosa advoga uma escrita comunicacional a partir de vínculos e relações da Comunicação. Entre protocolos e sugestões, afirma que a pesquisa é um retrato de reflexões que geram conhecimento como fruto de um objeto problematizado. Dentro desse percurso, Marialva aponta o estranhamento como passo para a problematização, a teorização e a construção de hipóteses, sempre pela ótica comunicacional.

A fim de saber como o trabalho científico contribui para a transformação social, o princípio de Marialva é de que o problema de pesquisa só se constitui pelo diálogo travado com a teoria por meio de apropriações conceituais, estabelecidas em cada investigação, por analogias, desconstruções, tensões e reflexões. E assim ela chega à discussão sobre a relação entre teoria e metodologia alegando que, sem teorização, não é possível formular problemas de pesquisa, construir caminhos metodológicos e dimensionar a forma como a análise será considerada e conduzida.

Sobre as hipóteses, diz que não há trabalho de natureza científica sem elas, que passam a receber atualmente codinomes como argumentos, indagações, proposições, etc., mas que continuam passíveis de verificação e detentoras de generalizações para comprovar ou não uma suposição inicial. 
Pela coleta de informações, análise e interpretação de dados é que Marialva Barbosa vai fundamentar sua proposta de escrita comunicacional, ideia sobre a qual sua defesa e proposta se fundamentam, a nosso juízo, em teorias explícitas, impressões implícitas e práticas de pesquisa atuais. Inicialmente, ela justifica que essa questão da escrita se constitui, há algum tempo, um incômodo para si mesma, por isso, a problematiza propondo uma escrita que reflita seu lugar de fala e cuja compreensão seja ponto de partida e de chegada.

Pelo que estamos chamando de teorias explícitas, a autora recupera alguns pressupostos teóricos de Michel de Certeau e de Muniz Sodré. O primeiro fala da escrita como uma servidão do discurso imposta à pesquisa. Já o segundo entende a transformação do mundo na perspectiva comunicacional dos vínculos e das relações. Em diálogo com esses autores, Marialva pondera que não há uma escrita da comunicação em essência.

Sobre as duas últimas categorizações que propomos, visualizamos um diálogo com outras apropriações de nossas próprias vivências em outras apropriações conceituais e que diretamente, no livro, não estão contempladas. Para entrar nisso, a autora analisa teses que selecionam documentos, fotografias, entrevistas e observação como ferramentas de pesquisa. Dos documentos, das fotografias e da observação, conseguimos visualizar um diálogo com o que Ciro Marcondes Filho chamava de incorpóreo, o instante abstrato da realização da Comunicação. E pelas entrevistas, o encontro com o outro e o ambiente, quando considerados, nos aludem ao que Cremilda Medina trata por diálogo possível. 
Estes dois fatores acima mencionados e mais a noção de comum, de Muniz Sodré, sustentando os vínculos e as relações, além de algumas constatações afetivas nas opções metodológicas de algumas teses observadas são os caminhos encontrados por Marialva Barbosa para propor rupturas, moldar os cenários de pesquisa, defender uma escrita comunicacional e acreditar que a Comunicação é a Ciência do século XXI.

\section{Referências}

BARBOSA, Marialva. Comunicação e método: cenários e práticas de pesquisa. Rio de Janeiro: Mauad X, 2020.

\section{Dados do autor}

\section{Rodrigo Gabrioti}

ORCID iDhttps://orcid.org/0000-0001-6745-3600

Universidade Metodista de São Paulo

Doutor em Comunicação pela Universidade Metodista de São Paulo (UMESP) na Linha de Pesquisa 1 - Comunicação Midiática nas Interações Sociais sob orientação do Prof. Dr. José Marques de Melo. Graduado em Jornalismo pela Universidade de Sorocaba (2004) onde também cursou o Mestrado em Comunicação e Cultura (2009). Editor-chefe do Tem Notícias, telejornal da TV TEM, emissora afiliada da Rede Globo, em Sorocaba (SP). MBA completo em Gestão de Marketing pela ESAMC Sorocaba. Professor do curso de Comunicação Social - Jornalismo na Athon Educacional, antiga ESAMC Sorocaba, onde leciona as disciplinas Teoria e Conceitos do Jornalismo, Gêneros e Práticas do Jornalismo, Rádio e TV - Produção/Redação, Jornalismo Multimídia, Mídia Impressa - Redação/ Produção. Orienta trabalhos de conclusão de curso na Graduação. Foi professor concursado da disciplina Reportagem e Entrevista Jornalística da Universidade Municipal de São Caetano do Sul (USCS). Integra o Grupo de Pesquisa Mídia, Culturas e Tecnologias Digitais na América Latina, da INTERCOM. Diretor adjunto de Projetos da Intercom, gestão 2020-2023. 